\title{
Favorable Effects of Flaxseed Supplemented Diet on Liver and Kidney Functions in Hypertensive Wistar Rats
}

\author{
Widad M. Al- Bishri* \\ Department of Biochemistry, College of Science for Girls, King Abdulaziz University, Jeddah 21589, Saudi Arabia
}

\begin{abstract}
Hypertension is a major risk factor for cardiovascular diseases and is detrimental to several organs including the liver and kidneys. The flaxseed-derived polyunsaturated fatty acids including the omega-3 and omega-6 essential fatty acids have been shown to blunt the effects of hypertension. It is however, unclear whether the flaxseed, which is rich in these essential fatty acids, could improve the liver and kidney dysfunctions observed in the hypertensive condition. To test this, functional markers of the liver and kidneys, including aspartate aminotransferase (AST), alanine aminotransferase (ALT), blood urea nitrogen (BUN), uric acid (UA), creatinine, and renin were examined in hypertensive male Wistar rats fed a flaxseed diet. Normotensive rats maintained on a standard diet were rendered hypertensive with a daily administration of cyclosporin A (CYS) $(25 \mathrm{mg} / \mathrm{kg})$ for 4 weeks. Subsequently, hypertensive rats were either fed a standard diet alone or a flaxseed-supplemented standard diet (FLX; $10 \% \mathrm{~W} / \mathrm{W})$ for 8 weeks. Compared to normotensive rats, standard diet-fed hypertensive rats had significantly elevated blood pressure, altered lipid profile, and increased plasma levels of tissue markers measured immediately following the CYS treatment and thereafter at 4 and 8 week intervals. On the other hand, rats fed the FLXsupplemented diet had significantly lower blood pressure, an improved lipid profile and decreased tissue marker levels measured after 4 and 8 week durations. The data demonstrate for the first time the favourable effects of FLX in improving liver and kidney functions in the hypertensive condition. These effects are likely to be mediated by the alpha-linolenic acid (ALA) and linoleic acid (LA) contents of flaxseed oil due to its demonstrated ability to lower the blood pressure.
\end{abstract}

Key words: Flaxseed, hypertension, liver, kidney

\section{INTRODUCTION}

Dietary intervention using-plant based products, has long been considered a better strategy for either preventing or reducing the progression of chronic diseases. This is largely due to the affordability of these products along with fewer side effects they produce compared to the drugs administered under a pharmacological approach ${ }^{1)}$. The flaxseed, due to its diverse active components, is known to possess multiple health benefits against cardiovascular diseases, dyslipidemia, diabetes, obesity, and cancer $^{2-5)}$. Flax (Linum usitatissimum), a nutritionally important oil seed plant, belongs to the Linaceae family. Flaxseed is an excellent source of oil, protein and dietary fibre as well as the phytochemical antioxidant, lignan (secoisolariciresinol diglucoside $)^{6,7)}$. Flaxseed oil is rich in ALA, an omega-3 fatty acid and LA, an omega-6 fatty $\operatorname{acid}^{7,8)}$.
Hypertension is a chronic medical condition characterized by sustained elevated blood pressure ${ }^{9)}$. Several studies have indicated that a deficiency of ALA leads to the development of hypertension and the supplementation of flaxseed oil reverses the process and normalizes blood pressure $^{7,10-12)}$. Hypertension is known to be detrimental to multiple organs including the liver and kidneys. Therefore, the present study was undertaken to examine whether flaxseed, with its major essential fatty acid content, could alleviate hypertension-induced liver and kidney dysfunctions and restore the functional markers of these organs. Therefore, we measured the effects of the flaxseed-supplemented diet on blood pressure, liver markers including aspartate AST and ALT. The kidney markers included BUN, UA, creatinine, and renin. These were all investigated in hypertensive male Wister rats and compared to normoten-

\footnotetext{
*Correspondence to: Widad M. Al- Bishri, Department of Biochemistry, College of Science for Girls, King Abdulaziz University, Jeddah 21589, Saudi Arabia

E-mail: wad.m2012@ hotmail.com

Accepted March 21, 2013 (received for review November 29, 2012)

Journal of Oleo Science ISSN 1345-8957 print / ISSN 1347-3352 online

http://www.jstage.jst.go.jp/browse/jos/ http://mc.manusriptcentral.com/jjocs
} 
sive rats fed a standard diet.

\section{EXPERIMENTAL}

\subsection{Animals}

This study was conducted in accordance with the guidelines set by the ethical committee of King Abdulaziz University, Jeddah, Saudi Arabia. Male Wistar albino rats, 8 weeks old and 150-170 g in weight were acclimated to the environmental conditions of the animal housing facility for two weeks under a $12 \mathrm{~h}$ light-dark cycle and at $22 \pm 3^{\circ} \mathrm{C}$ temperature. Rats were provided with water and a normal standard diet ad libitum.

\subsection{Experimental diets}

Compositions of the standard diet and the flaxseed-supplemented standard diet are presented in Table 1. Freshly ground flaxseed was obtained locally, roasted to remove cyanides, crushed and mixed with a standard chow diet at $10 \%(\mathrm{~W} / \mathrm{W})$ concentration. The diet was then moistened, re-pelleted, and fan-dried. Diets were refrigerated and protected from light. The flaxseed concentration used in this study $(10 \mathrm{~g} / 100 \mathrm{~g})$ is similar to that used in studies reporting health-related benefits. Composition of the flaxseed supplemented diet $(10 \%$ W/W $)$ was calculated based on a 90:10 proportion of a standard diet and ground flaxseed respectively $^{13)}$. The quantity of food consumed per day by each group of rats was calculated by subtracting the weight of the leftover chow from the weight of the initial chow provided. Total energy consumed per day was calculated based on the energy content of each diet and the amount of each diet consumed.

\subsection{Experimental design}

Rats were randomly assigned to three groups designated as control (normotensive, standard diet fed), CYS (hypertensive, standard diet fed) and CYS + FLX (hypertensive, flaxseed-supplemented standard diet fed)groups. Each

Table 1 Proximate major nutrients of standard diet and flaxseed supplemented diets.

\begin{tabular}{lccc}
\hline \multicolumn{1}{c}{ Nutrient } & SD & FLX $^{\mathrm{a}}$ & SD+FLX (90:10) \\
\hline Protein $(\mathrm{g})$ & 20 & 18.3 & 19.8 \\
Fat $(\mathrm{g})$ & 3 & 42.2 & 6.9 \\
Carbohydrate $(\mathrm{g})$ & 56.4 & 29 & 53.6 \\
Fiber $(\mathrm{g})$ & 5.5 & 27.3 & 7.7 \\
Water $(\mathrm{g})$ & 8.75 & 7.0 & 8.6 \\
Energy (Kcal) & 285 & 535 & 310 \\
\hline
\end{tabular}

SD- standard diet, FLX- flaxseed diet, SD+FLX- flaxseed supplemented standard diet. ${ }^{\mathrm{a}}$ Ref.13 group contained 10 rats. Hypertension in the CYS group was induced by a daily subcutaneous administration of CYS (25 mg/kg diluted in $1 \mathrm{ml} / \mathrm{kg}$ olive oil)administered over a four week period. The CYS is an effective agent for the induction of hypertension and the CYS induced hypertensive rat models have been shown to exhibit the typical hypertensive characteristics ${ }^{14,15)}$. The mechanism of hypertension induction by CYS involves the immunosuppression mediated by the calcineurin inhibition, which is suggested to block either the T-cell signaling or the renal afferent activation $^{16,17)}$. Normotensive rats received sham treatment. Hypertensive status was confirmed by measuring the blood pressure by the tail-cuff method. Rats in the control, CYS and CYS + FLX groups were initially maintained on a standard diet. This diet was replaced with flaxseed-supplemented diet for rats in the CYS + FLX group from the $29^{\text {th }}$ day following the four week (28 days) cyclosporine A treatment. Diet supplementation was continued for eight weeks. Blood pressure was measured by the tail-cuff method and blood samples were collected by a retro-orbital bleeding at the beginning of the diet supplementation (baseline) and thereafter at 4- and 8- week intervals. Blood pressure was measured prior to the blood collection to avoid an influence of the blood collection procedure on the blood pressure. Plasma was separated from the blood by gradient centrifugation using Ficoll-Paque PLUS (GE Health Care, Germany) and stored at $-80^{\circ} \mathrm{C}$ until analyzed.

\subsection{Biochemical measurements}

Plasma total-cholesterol and triacylglycerol(TAG)were measured using a fully automated analyzer (Konelab Instruments, Espoo, Finland). HDL-cholesterol levels were determined by phosphotungstic acid/magnesium chloride precipitation (Kone Instruments, Espoo, Finland). LDLcholesterol was calculated using Friedewald equation. Plasma UA and creatinine were measured using an assay kit by following the manufacturer's instructions (BioAssay Systems, CA. USA). The BUN, was assayed by using a commercially available kit (Arbor Assays MI. USA), and renin activity was determined by using a renin assay kit (R\&D Systems, MN, USA). Plasma AST and ALT activities were measured by following the manufacturer's instructions on their kit (Cayman Chemical Company, MI. USA).

\subsection{Statistical analysis}

SPSS statistical software was utilized for the data analysis. Data is represented by mean \pm standard deviation. Assumptions of normality and homogeneity of variance were checked. Square root or log transformation was done for skewed data. An analysis of variance (ANOVA) was performed between groups of treatments for various parameters. A Bonferroni post-hoc test was done for multiple comparisons following the ANOVA. The level of significance was given at $p<0.05$. 


\section{RESULTS}

\subsection{Body weight, food and energy intakes}

To assess the effects of food and energy intakes on body weight, these parameters were compared among the studied groups. Food intake (g/day) among the control, CYS and CYS + FLX groups was not significantly different at baseline $(23 \pm 1.8,22 \pm 1.3$, and $22 \pm 1.5 \mathrm{~g}$ /day, respectively; $p>0.05)$, at 4 weeks $(23 \pm 2.1,23 \pm 1.4$, and $22 \pm 1.8 \mathrm{~g} /$ day, respectively; $p>0.05)$ and at 8 weeks $(23 \pm 1.6,22 \pm 1.7$, and $23 \pm 1.5 \mathrm{~g} /$ day, respectively; $p>0.05)$. Energy intakes (Kcal/day) among the control, CYS and CYS + FLX groups was also comparable at baseline (65.5 $\pm 5.13,58.96 \pm 3.7$, $68.2 \pm 4.65 \mathrm{Kcal} /$ day, respectively; $p>0.05$ ), at 4 weeks $(65.5 \pm 5.98,65.5 \pm 3.99$ and $68.2 \pm 4.65 \mathrm{Kcal} /$ day, respectively; $p>0.05)$ and at 8 weeks $(65.5 \pm 4.56,58.96 \pm 4.84$ and $71.3 \pm 4.65 \mathrm{Kcal} /$ day, respectively; $p>0.05)$. Similarly, no significant change in the body weights (g)were observed between the control, CYS and CYS + FLX groups at baseline (525 $\pm 28,521 \pm 31$ and $522 \pm 33$ g, respectively; $p$ $>0.05)$, at 4 weeks $(521 \pm 30,524 \pm 29$ and $525 \pm 28$ g, respectively; $p>0.05)$ and at 8 weeks $(528 \pm 33,520 \pm 35$ and $520 \pm 34 \mathrm{~g}$, respectively; $p>0.05$ ) of the feeding duration.

\subsection{Effect of the flaxseed diet on lipid profiles}

Effects of the flaxseed diet on lipid profiles in the control,
CYS and CYS + FLX groups are presented in Table 2. Compared to rats in the control group, the CYS group had significantly elevated systolic and diastolic blood pressures, total cholesterol, TAG, and LDL-cholesterol with significantly decreased HDL-cholesterol at baseline, 4 and 8 weeks. These levels were comparable to those in the CYS + FLX group at baseline. However, the CYS + FLX group exhibited significantly decreased systolic and diastolic blood pressures, total cholesterol, TAG, and LDL-cholesterol along with significantly increased HDL-cholesterol levels after 4 and 8 weeks compared to time matched CYS group rats.

\subsection{Effect of the flaxseed diet on AST and ALT}

Effects of the FLX diet on AST and ALT are presented in Fig. 1. At baseline the AST and ALT levels were significantly elevated $(p<0.05$ and $p<0.01$, respectively) in the CYS and CYS + FLX groups compared to the control group. These levels remained significantly elevated $(p<0.05$ and $p$ $<0.01$ respectively) when tested after 4 and 8 weeks in the CYS group compared to the time-matched control. Alternatively, these levels were significantly decreased $(p<0.05$ and $p<0.01$, respectively) after 4 weeks and remained significantly lower $(p<0.05$ and $p<0.01$, respectively $)$ at 8 weeks in the CYS + FLX group compared to the timematched CYS group.

Table 2 Lipid profile in control and hypertensive rats on standard or FLX supplemented diet.

\begin{tabular}{|c|c|c|c|c|c|}
\hline Parameters & Duration & $\begin{array}{l}\text { Control } \\
(\mathrm{N}=10)\end{array}$ & $\begin{array}{c}\text { CYS } \\
(\mathrm{N}=10)\end{array}$ & $\begin{array}{c}\text { CYS + FLX } \\
(\mathrm{N}=10)\end{array}$ & $\mathrm{P}$ value \\
\hline \multirow[t]{3}{*}{$\mathrm{SBP}(\mathrm{mmHg})$} & Baseline & $108.5 \pm 18.1$ & $130.8 \pm 11.9 *$ & $131.0 \pm 21.7 *$ & $<0.001$ \\
\hline & 4 weeks & $106.0 \pm 18.9$ & $128.0 \pm 13.1 *$ & $116.0 \pm 19.4^{\dagger}$ & $<0.001$ \\
\hline & 8 weeks & $105.2 \pm 17.5$ & $125.7 \pm 21.7 *$ & $114.0 \pm 17.3^{\dagger}$ & $<0.001$ \\
\hline \multirow[t]{3}{*}{ DBP (mmHg) } & Baseline & $67.6 \pm 14.4$ & $117.8 \pm 21.7 *$ & $90.0 \pm 13.5 *$ & $<0.001$ \\
\hline & 4 weeks & $72.1 \pm 21.0$ & $113.0 \pm 18.7 *$ & $87.0 \pm 11.9^{\dagger}$ & $<0.001$ \\
\hline & 8 weeks & $67.7 \pm 23.0$ & $116.0 \pm 15.6 *$ & $93.0 \pm 14.3^{\dagger}$ & $<0.001$ \\
\hline \multirow[t]{3}{*}{ Cholesterol (mmol/1) } & Baseline & $1.2 \pm 0.24$ & $2.3 \pm 0.28^{*}$ & $2.2 \pm 0.27^{*}$ & $<0.001$ \\
\hline & 4 Weeks & $1.3 \pm 0.25$ & $2.4 \pm 0.30 *$ & $1.7 \pm 0.26^{\dagger}$ & $<0.001$ \\
\hline & 8 Weeks & $1.3 \pm 0.23$ & $2.4 \pm 0.31 *$ & $1.6 \pm 0.25^{\dagger}$ & $<0.001$ \\
\hline \multirow[t]{3}{*}{ TAG (mmol/1) } & Baseline & $0.17 \pm 0.05$ & $0.32 \pm 0.12 *$ & $0.35 \pm 0.13^{*}$ & $<0.01$ \\
\hline & 4 Weeks & $0.18 \pm 0.06$ & $0.33 \pm 0.08 *$ & $0.24 \pm 0.07^{\dagger}$ & $<0.001$ \\
\hline & 8 Weeks & $0.18 \pm 0.07$ & $0.35 \pm 0.08 *$ & $0.23 \pm 0.08^{\dagger}$ & $<0.001$ \\
\hline \multirow[t]{3}{*}{ HDL-cholesterol (mmol/l) } & Baseline & $0.68 \pm 0.06$ & $0.45 \pm 0.06^{*}$ & $0.43 \pm 0.05^{*}$ & $<0.001$ \\
\hline & 4 Weeks & $0.67 \pm 0.07$ & $0.43 \pm 0.05^{*}$ & $0.58 \pm 0.07^{\dagger}$ & $<0.001$ \\
\hline & 8 Weeks & $0.68 \pm 0.07$ & $0.42 \pm 0.04 *$ & $0.60 \pm 0.08^{\dagger}$ & $<0.001$ \\
\hline \multirow[t]{3}{*}{ LDL-cholesterol (mmol/l) } & Baseline & $0.24 \pm 0.05$ & $0.55 \pm 0.08^{*}$ & $0.56 \pm 0.08^{*}$ & $<0.001$ \\
\hline & 4 Weeks & $0.25 \pm 0.06$ & $0.56 \pm 0.09 *$ & $0.35 \pm 0.06^{\dagger}$ & $<0.001$ \\
\hline & 8 Weeks & $0.26 \pm 0.07$ & $0.55 \pm 0.09 *$ & $0.32 \pm 0.05^{\dagger}$ & $<0.001$ \\
\hline
\end{tabular}

CYS-cyclosporine A; FLX-flaxseed; SBP- systolic blood pressure; DBP- diastolic blood pressure; TAGtriacylglycerol; *significantly different compared to control; ${ }^{\dagger}$ significantly different compared to CYS. 
A

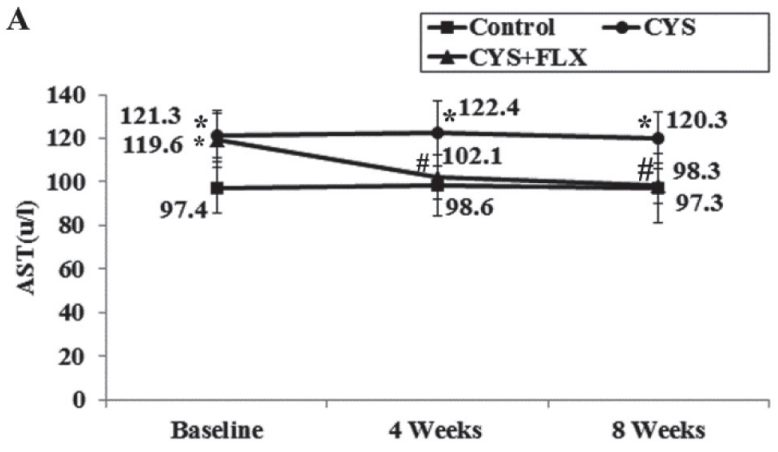

B

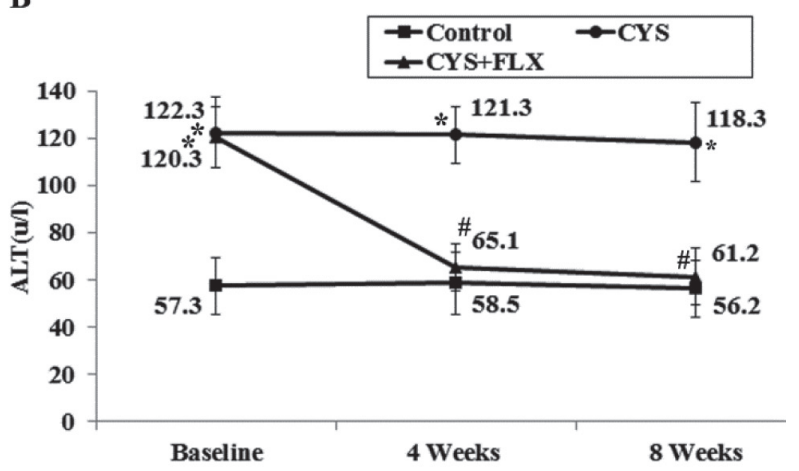

Fig. 1 Effects of a flaxseed-supplemented diet on aspartate aminotransferase (AST) and alanine aminotransferase (ALT) in hypertensive rats. Normotensive rats on a standard diet were rendered hypertensive with cyclosporin A. Hypertensive rats were either fed a standard diet alone or the flaxseed-supplemented standard $\operatorname{diet}(10 \% \mathrm{~W} /$ W) for 8 weeks. Blood samples from control (normotensive), CYS (hypertensive) and CYS+FLX (flaxseed-supplemented diet and hypertensive) rats were collected at baseline, 4 and 8 week intervals and plasma levels of AST and ALT were measured. * Significantly different from control $(p$ $<0.05, p<0.01$ for AST and ALT, respectively), \# significantly different from CYS $(p<0.05, p<$ 0.01 for AST and ALT, respectively).

\subsection{Effect of the flaxseed diet on BUN and UA}

The BUN and UA levels in the control, CYS and CYS+ FLX groups are provided in Fig. 2. The BUN and UA levels were significantly increased at baseline in the CYS and CYS + FLX groups rats compared to the normotensive control group $(p<0.001$ and $p<0.01$, respectively). These levels remained significantly elevated in the CYS group at 4 and 8 weeks compared to the time-matched controls $(p<0.001$ and $p<0.01$, respectively). In contrast, rats in the CYS + FLX group showed significantly reduced BUN and UA levels after 4 and 8 weeks in comparison to time-matched levels measured in the CYS group $(p<0.01$ and $p<0.01$ re-
A

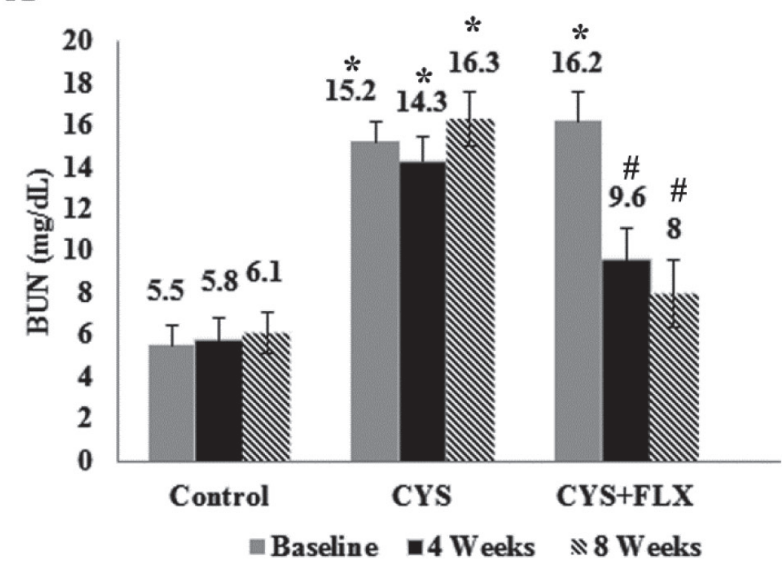

B

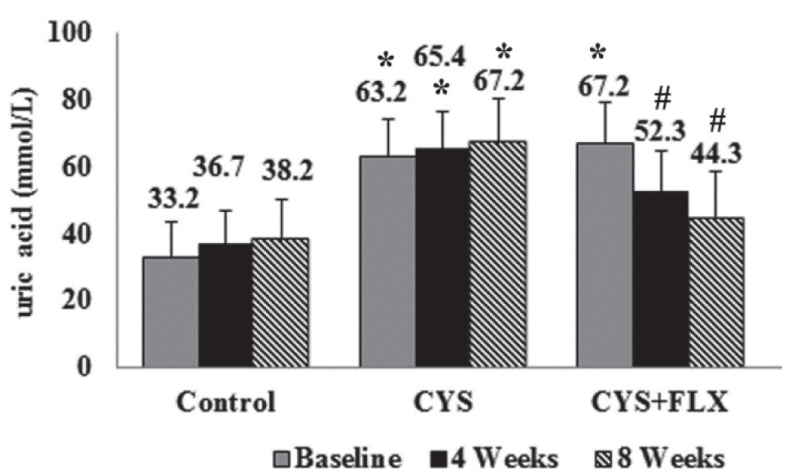

Fig. 2 Effects of a flaxseed-supplemented diet on blood urea nitrogen (BUN) and UA levels in hypertensive rats. Normotensive rats on a standard diet were rendered hypertensive with cyclosporin A. Hypertensive rats were either fed a standard diet alone or the flaxseed-supplemented standard diet $(10 \% \mathrm{~W} / \mathrm{W})$ for 8 weeks. Blood samples from normotensive (control), hypertensive (CYS) and diet-supplemented hypertensive (CYS+FLX) rats were collected at baseline, 4 and 8 week intervals and plasma levels of BUN and UA were measured. * Significantly different from control $(p<0.001, p<0.01$ for BUN and UA, respectively), \# significantly different from CYS ( $p$ $<0.01, p<0.01$ for BUN and UA, respectively).

spectively).

\subsection{Effect of the flaxseed diet on creatinine and renin}

Effects of the flaxseed on creatinine and renin levels are shown in Fig. 3. Compared to control rats, the CYS group demonstrated significantly increased creatinine and renin levels at baseline and thereafter at 4 and 8 week durations $(p<0.01$, respectively). The levels of creatinine and renin in the CYS + FLX group were also comparable to baseline 
A

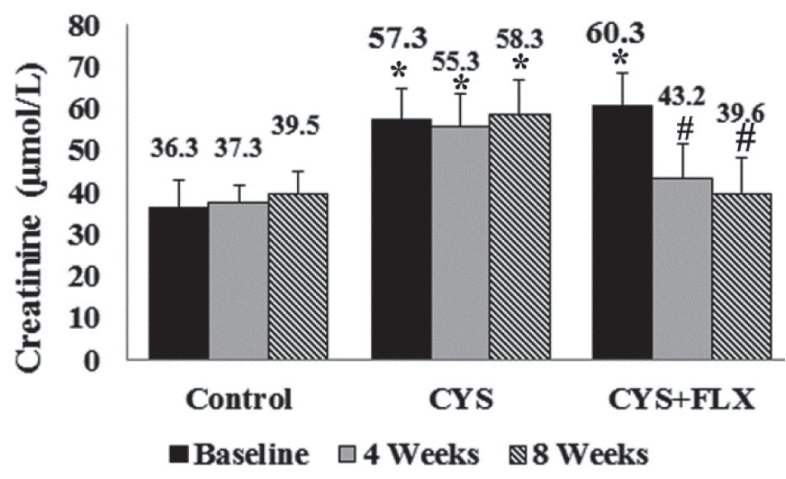

B

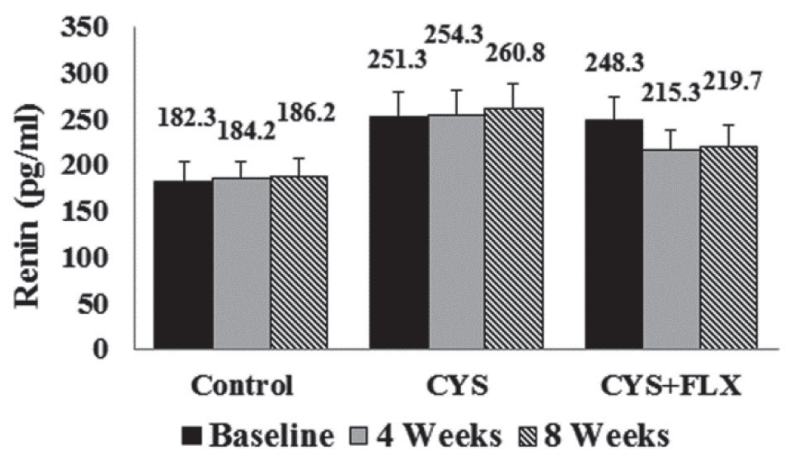

Fig. 3 Effects of a flaxseed-supplemented diet on creatinine and renin in hypertensive rats. Normotensive rats on a standard diet were rendered hypertensive with cyclosporin A. Hypertensive rats were either fed a standard diet alone or the flaxseed-supplemented standard diet $(10 \% \mathrm{~W} / \mathrm{W})$ for 8 weeks. Blood samples from normotensive (control), hypertensive (CYS) and diet-supplemented hypertensive (CYS+FLX) rats were collected at baseline, 4 and 8 week intervals and plasma levels of creatinine and renin were measured. * Significantly different from control $(p<0.01, p<0.01$ for creatinine and renin, respectively, \# significantly different from CYS $(p<0.05, p<0.05$ for creatinine and renin, respectively).

levels found in CYS group rats $(p<0.01)$, however, these levels were significantly reduced after 4 weeks $(p<0.05)$ and remained significantly low even after 8 weeks $(p<0.05)$ compared to those in the time-matched CYS group.

\section{DISCUSSION}

Functional foods are considered superior in the prevention and treatment of several chronic diseases mainly due to their reduced side effects. Flaxseed is an excellent source of oil, protein and dietary fibre as well as a rich source of the phytochemical antioxidant, lignan ${ }^{6,7)}$. Flaxseed oil is rich in ALA and $\mathrm{LA}^{7,8)}$. Fibre and lignan contents of flaxseed are reported to reduce both the total- and LDLcholesterol levels ${ }^{18)}$. Meanwhile, the ALA content of flax oil is suggested to be antiatherogenic because of its antiinflammatory and antiproliferative properties ${ }^{19,20)}$. Flaxseed gained further importance following the identification of its antioxidant property, which is essential in blocking oxidative stress, and is believed to be central to the initiation and progression of a majority of chronic disease ${ }^{21-23)}$. Hypertension is a major risk factor of cardiovascular diseases and is also known to negatively impact various organs including the liver and kidneys. Several studies have reported the positive effects of flaxseed oil to normalize blood pressure and to diminish the level of hypertension ${ }^{10-12)}$. Considering that hypertension negatively impacts liver and kidney functions, the present study was undertaken to examine whether flaxseed, with its major essential fatty acid content, could alleviate the hypertension and its negative effects on liver and kidney functions.

In the present study, the increased blood pressure and altered lipid parameters in cyclosporine-treated rats confirms the hypertensive state and its unfavourable effects on lipid profiles. Significant reductions in the blood pressure and favourable improvements in lipid profiles following the supplementation of a flaxseed diet is consistent with the antihypertensive and antidyslipidemic characteristics of flaxseed or its individual components ${ }^{7,10-12,23-25)}$. The antihypertensive nature of flaxseed can be explained by several possible mechanisms. Angiotensin converting enzyme, which assists in regulating blood pressure, is inhibited by the ALA of flaxseed at both the phenotypic and genetic levels in spontaneously hypertensive rats $(\mathrm{SHR})^{10,21-23)}$. Likewise, supplementation of flaxseed oil lowered the blood pressure, body weight and adiposity in hypertensive rats $^{11)}$. A flaxseed diet has also been shown to act as vasorelaxant and restore the endothelial function in $\mathrm{SHR}^{26)}$. Hypertension may also increase several biochemical parameters associated with liver and kidney functions including AST, ALT, bilirubin, BUN, UA, creatinine and renin ${ }^{27,28)}$. Consistent with the detrimental effects of hypertension on the liver and kidneys, cyclosporine-treated hypertensive rats in the present study demonstrated significantly increased levels of these functional markers compared to normotensive rats.

Several studies have previously shown the positive effects of flaxseed or its components on liver and kidney functions in various pathological conditions. For example, flaxseed oil significantly reduced the AST and ALT enzyme levels and ablated the non-alcoholic fatty liver in hamsters along with acute and chronic arthritis in albino rat models ${ }^{29,30)}$. Similarly, flaxseed oil has been shown to lower the AST and 
ALT in radiation-induced hepatotoxicity in mice ${ }^{23)}$. Further, studies have reported the positive effects of flaxseed oil, or flaxseed per se, on kidney functions. Treatment with flaxseed oil significantly reduced the sodium nitroprusside and L-arginine-induced increase in BUN levels in the plasma and kidneys of rats $^{31,32)}$. Flaxseed-supplemented diets as well as flax oil, markedly lowered the UA level in healthy rats and in the condition of renal toxicity ${ }^{33,34)}$. Additionally, flaxseed oil or flaxseed diets have lowered the serum and kidney creatinine levels in several pathological and experimental conditions ${ }^{31,32,35,36)}$. Flaxseed oil has been shown to inhibit the renin mRNA levels in $\mathrm{SHR}^{37)}$. Collectively, these data clearly demonstrate the protective effects of flaxseed or flaxseed oil in improving the liver and kidney functions in various pathophysiological environments. Consistent with these observations, the present study shows that a flaxseed-supplemented diet significantly lowered the plasma levels of liver functional markers including AST and ALT and the kidney markers including BUN, UA, creatinine and renin in hypertensive rats. This suggests that flaxseed has the ability to not only attenuate hypertension but also to exert beneficial effects on hypertension-induced alterations in liver and kidney functions.

\section{CONCLUSION}

Flaxseed oil has been directly linked to restoring blood pressure and diminishes hypertension as well as restoring functional markers of liver and kidney, albeit in pathological conditions other than hypertension. It is likely that the ALA and LA content of flax oil, which is the major constituent of flaxseed, exerted these beneficial effects on liver and kidney functions in the present study. This is the first study to identify the favourable effects of the flaxseed-supplemented diet on liver and kidney function in a hypertensive setting as well as confirm its antihypertensive and antidyslipidemic effects. Thus, the results of this study would suggest that a regular consumption of diets rich in essential oils may lead to positive health effects.

\section{ACKNOWLEDGMENTS}

Author thanks the Deanship of Scientific Research, King Abdulaziz University, Jeddah, Saudi Arabia for financial (Research Grant No. 441/363/431) and technical support. Author also thanks Benjamin Vinodson for statistical analysis of the data.

\section{References}

1) Duncan, A. M.; Phipps, W. R.; Kurzer, M. S. Phyto-oes- trogens. Best Pract. Res. Clin. Endocrinol. Metab. 17, 253-271 (2003).

2) Peterson, J.; Dwyer, J.; Adlercreutz, H.; Scalbert, A.; Jacques, P.; McCullough, M. L. Dietary lignans: physiology and potential for cardiovascular disease risk reduction. Nutr. Rev. 68, 571-603(2010).

3) Bhathena, S. J.; Velasquez, M. T. Beneficial role of dietary phytoestrogens in obesity and diabetes. Am. J. Clin. Nutr. 76, 1191-1201(2002).

4) Makni, M.; Sefi, M.; Garouiel, M.; Fetoui, H.; Boudawara, T.; Zeghal, N. Dietary polyunsaturated fatty acid prevents hyperlipidemia and hepatic oxidant status in pregnant diabetic rats and their macrosomic offspring. J. Diabetes. Complications. 25, 267-274 (2011).

5) Lehraiki, A.; Attoumbré, J.; Bienaimé, C.; Matifat, F.; Bensaddek, L.; Nava-Saucedo, E.; Fliniaux, M.A.; Ouadid-Ahidouch, H.; Baltora-Rosset, S. Extraction of lignans from flaxseed and evaluation of their biological effects on breast cancer MCF-7 and MDA-MB-231 cell lines. J. Med. Food. 13, 834-841 (2010).

6) Bhatty, R. S. 1995. Nutrient composition of whole flaxseed and flaxseed meal. In Flaxseed in Human Nutrition (S. C. Cunnane and L. U. Thompson, eds.) pp. 22-42, AOCS Press, Champaign, IL.

7) Bassett, C. M.; Rodriguez-Leyva, D.; Pierce, G. N. Experimental and clinical research findings on the cardiovascular benefits of consuming flaxseed. Appl. Physiol. Nutr. Metab. 34, 965-974(2009).

8) Conner, W. E. Importance of n-3 fatty acids in health and disease. Am. J. Clin. Nutr. 71, 171S-175S (2000).

9) Lackland, D. T.; Egan, B. M. The dominant role of systolic hypertension as a vascular risk factor: evidence from the southeastern United States. Am. J. Med. Sci. 318, 365-368 (1999).

10) Ogawa, A.; Suzuki, Y. Dietary alpha-linolenic acid inhibits angiotensin-converting enzyme activity and mRNA expression levels in the aorta of spontaneously hypertensive rats. J. Oleo Sci. 58, 355-360 (2009).

11) Begg, D. P.; Sinclair, A. J.; Stahl, L. A.; Premaratna, S. D.; Hafandi, A.; Jois, M.; Weisinger, R. S. Hypertension induced by omega-3 polyunsaturated fatty acid deficiency is alleviated by alpha-linolenic acid regardless of dietary source. Hypertens. Res. 33, 808-813(2010).

12) Singer, P. Alpha-linolenic acid vs. long-chain n-3 fatty acids in hypertension and hyperlipidemia. Nutrition 8, 133-135(1992).

13) Daun, J. K., Barthet, V. J., Chornick, T. L. and Duguid, S. 2003.Structure, composition, and variety development of flaxseed. In Flaxseedin Human Nutrition, 2nd Ed. (L. U. Thompson and S. C. Cunnane, eds.), pp. 1-40, AOCS Press, Champaign, IL.

14) Reis, F.; Parada, B.; Teixeira de Lemos, E.; Garrido, P.; Dias, A.; Piloto, N.; Baptista, S.; Sereno, J.; Eufrásio, P.; 
Costa, E.; Rocha-Pereira, P.; Santos-Silva, A.; Figueiredo, A.; Mota, A.; Teixeira, F. Hypertension induced by immunosuppressive drugs: a comparative analysis between sirolimus and cyclosporine. Transplant. Proc. 41, 868-873 (2009).

15) Louhelainen, M.; Merasto, S.; Finckenberg, P.; Lapatto, R.; Cheng, Z. J.; Mervaala, E. M. Lipoic acid supplementation prevents cyclosporine-induced hypertension and nephrotoxicity in spontaneously hypertensive rats. J. Hypertens. 24, 947-56 (2006) .

16) Lyson, T.; Ermel, L. D.; Belshaw, P. J.; Alberg, D. G.; Schreiber, S. L.; Victor, R. G. Cyclosporine- and FK506-induced sympathetic activation correlates with calcineurin-mediated inhibition of T-cell signaling. Circ. Res. 73, 596-602 (1993).

17) Zhang, W.; Victor, R. G. Calcineurin inhibitors cause renal afferent activation in rats: a novel mechanism of cyclosporine-induced hypertension. Am. J. Hypertens. 13, 999-1004(2000).

18) Prasad, K. Hypocholesterolemic and antiatherosclerotic effect of flax lignan complex isolated from flaxseed. Atherosclerosis 179, 269-75(2005).

19) Razi, S. S.; Latif, M. J.; Li, X.; Afthinos, J. N.; Ippagunta, N.; Schwartz, G.; Sagalovich, D.; Belsley, S. J.; Connery, C. P.; Jour, G.; Christofidou-Solomidou, M.; Bhora, F. Y. Dietary flaxseed protects against lung ischemia reperfusion injury via inhibition of apoptosis and inflammation in a murine model. J. Surg. Res. 171, e113-e121 (2011).

20) Velasquez, M. T.; Bhathena, S. J. Dietary phytoestrogens: a possible role in renal disease protection. Am. J. Kidney Dis. 37, 1056-1068(2001).

21) Udenigwe, C. C.; Aluko, R. E. Multifunctional cationic peptide fractions from flaxseed protein hydrolysates. Plant Foods Hum. Nutr. 67, 1-9 (2012).

22) Makni, M.; Sefi, M.; Fetoui, H.; Garouiel, M.; Gargouri, N. K.; Boudawara, T.; Zeghal, N. Flax and Pumpkin seeds mixture ameliorates diabetic nephropathy in rats. Food Chem. Toxicol. 48, 2407-2412(2010).

23) Bhatia, A. L.; Sharma, A.; Patni, S.; Sharma, A. L. Prophylactic effect of flaxseed oil against radiation-induced hepatotoxicity in mice. Phytother. Res. 21, 852859 (2007)

24) Makni, M.; Fetoui, H.; Gargouri, N. K.; Garouiel, M.; Zeghal, N. Antidiabetic effect of flax and pumpkin seed mixture powder: effect on hyperlipidemia and antioxidant status in alloxan diabetic rats. J. Diabetes Complications. 25, 339-345(2011).

25) Park, J. B.; Velasquez, M. T. Potential effects of lignanenriched flaxseed powder on bodyweight, visceral fat, lipid profile, and blood pressure in rats. Fitoterapia 83, 941-6(2012).

26) Talom, R. T.; Judd, S. A.; McIntosh, D. D.; McNeill, J. R. High flaxseed (linseed) diet restores endothelial func- tion in the mesenteric arterial bed of spontaneously hypertensive rats. Life Sci. 64, 1415-1425 (1999).

27) Torgerson, J. S.; Lindroos, A. K.; Sjöström, C. D.; Olsson, R.; Lissner, L.; Sjöström, L. Are elevated aminotransferases and decreased bilirubin additional characteristics of the metabolic syndrome? Obes. Res. 5, 105-114 (1997).

28) Saruta, T. Effects of nicardipine on blood pressure and renal function in elderly hypertensive patients with renal dysfunction. Am. Heart J. 117, 243-249 (1989).

29) Yang, S. F.; Tseng, J. K.; Chang, Y. Y.; Chen, Y. C. Flaxseed oil attenuates nonalcoholic fatty liver of hyperlipidemic hamsters. J. Agric. Food Chem. 57, 5078-5083 (2009).

30) Kaithwas, G.; Majumdar, D. K. Therapeutic effect of Linum usitatissimum (flaxseed/linseed) fixed oil on acute and chronic arthritic models in albino rats. Inflammopharmacology 18, 127-136 (2010).

31) Khan, M.; Priyamvada, S.; Khan, S.; Khan, S.; Naqshbandi, A.; Yusufi, A. Protective effect of $\omega-3$ polyunsaturated fatty acids (PUFAs) on sodium nitroprusside-induced nephrotoxicity and oxidative damage in rat kidney. Hum Exp. Toxicol. 31, 1035-1049 (2012).

32) Khan, M.; Priyamvada, S.; Khan, S.; Khan, S.; Naqshbandi, A.; Yusufi, A. Protective effect of $\omega-3$ polyunsaturated fatty acids (PUFAs) on L-arginine-induced nephrotoxicity and oxidative damage in rat kidney. Hum Exp. Toxicol. 31, 1035-1049 (2012).

33) Tomaz Pacheco, J.; Beltrame Daleprame, J.; Teles Boaventura, G. Impact of dietary flaxseed (linum usitatissimum) supplementation on biochemical profile in healthy rats. Nutr. Hosp. 26, 798-802 (2011).

34) Abdel Moneim, A. E.; Dkhil, M. A.; Al-Quraishy, S. The protective effect of flaxseed oil on lead acetate-induced renal toxicity in rats. J. Hazard. Mater. 194, 250-255 (2011).

35) Fernandes, M. B.; Caldas, H. C.; Martins, L. R.; Ferreira, C. C.; Baptista, M. A.; Fernandes, I. M.; AbbudFilho, M. Effects of polyunsaturated fatty acids (PUFAs) in the treatment of experimental chronic renal failure. Int. Urol. Nephrol. 44, 1571-1576(2012).

36) Ogborn, M. R.; Nitschmann, E.; Weiler, H.; Leswick, D.; Bankovic-Calic, N. Flaxseed ameliorates interstitial nephritis in rat polycystic kidney disease. Kidney Int. 55, 417-423 (1999).

37) Miyazaki, M.; Takemura, N.; Watanabe, S.; Hata, N.; Misawa, Y.; Okuyama, H. Dietary docosahexaenoic acid ameliorates, but rapeseed oil and safflower oil accelerate renal injury in stroke-prone spontaneously hypertensive rats as compared with soybean oil, which is associated with expression for renal transforming growth factor-beta, fibronectin and renin. Biochim. Biophys. Acta 1483, 101-110(2000). 